\title{
SHAPIRO SYNDROME WITH HYPOTHALAMIC HYPOTHYROIDISM
}

\author{
Ronaldo Arkader ${ }^{1}$, Carlos Augusto Takeuchi²
}

Shapiro syndrome, first described in 1969, is an extremely rare condition consisting of the clinical triad of recurrent hypothermia, sweating, and chills in the presence of agenesis of the corpus callosum. The periodicity of the hypothermic episodes ranges from hours to years, and episodes may last hours to weeks. Typically, but not invariably, there are associated central nervous system abnormalities affecting structures, particularly in the hypothalamus'. Central forms of hypothyroidism include secondary hypothyroidism, which is caused by TSH deficien$c y$, and tertiary hypothyroidism, which is caused by TRH deficiency ${ }^{2}$.

We describe a previously healthy boy with Shapiro syndrome and hypothalamic hypothyroidism treated with thyroxine and cyproheptadine.

\section{CASE}

A 8-year-old boy in otherwise good health, who, since 5 years of age, presented with sporadic episodes of nocturnal hypothermia, associated with pallor and profuse sweating. The axillary body temperature during the episodes was $34.5^{\circ} \mathrm{C}$, lasting for approximately an hour. The episodes recurred 10 or 12 times a month during sleep. Blood analysis indicated a normal complete blood count and blood chemistry. Morning cortisol (am), prolactin, growth hormone, $\mathrm{LH}$ and FSH were also normal for age. Thyroid stimulating hormone was $4.8 \mu \mathrm{U} / \mathrm{mL}$ (normal range 0.4 to 4.0 ), free thyroxine $\left(\mathrm{FT}_{4}\right.$ ) was $1.3 \mu \mathrm{IU} / \mathrm{mL}$ (range 4-56). After exclude other causes of hipothyreoidism we performed a TRH stimulation test for the differentiation of hypothalamic from pituitary disease. Plasma TSH was measured before and 15, 30, 45, 60,120 , and $180 \mathrm{~min}$ after iv administration of TRH $\left(10 \mu \mathrm{g} \cdot \mathrm{kg}^{-1}\right) \mathrm{An}$ adequate TSH response to TRH was defined by a peak concentration exceeding $15 \mu \mathrm{U} / \mathrm{ml}$ and return to baseline within $3 \mathrm{~h}$. A TRH test demonstrated an blunted response (TSH: basal $2.1 \mu \mathrm{U} / \mathrm{mL}$ and a peak $4.3 \mu \mathrm{U} / \mathrm{mL}$ - deltaTSH <4.5) Hypothalamic morphology was assessed using magnetic resonance imaging (MRI) (Figure).

The child mother signed the informed consent for publish the case

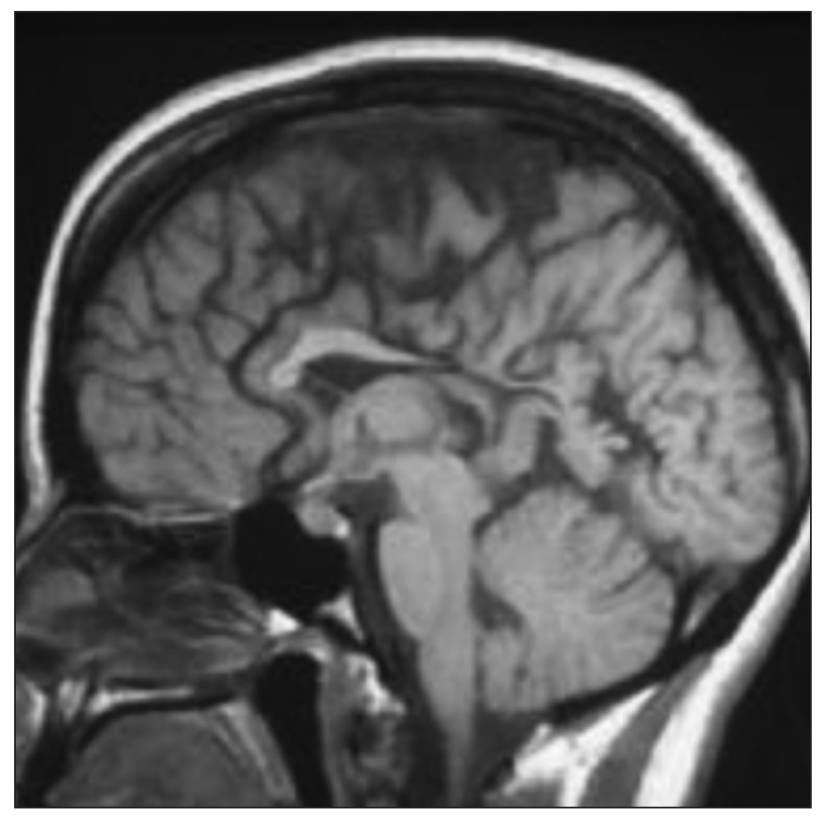

Figure. Sagittal T7-weighted MRI of the brain shows partial agenesis of the corpus callosum.

\section{DISCUSSION}

The majority of pediatric cases of hypothermia, defined as a core body temperature below $35^{\circ} \mathrm{C}$, are caused by environmental exposures. Nonenvironmental hypothermia in pediatric patients is uncommon. Life-threatening causes of nonenvironmental hypothermia include sepsis, drug ingestions, brain tumors, and endocrinologic abnormalities. Cyproheptadine, an antiserotonergic medication, has been shown to abort or control these episodes in some patients'.

The symptoms of central hypothyroidism include fatigue, apathy, weight gain, dry skin, constipation and cold intolerance deficiency of TRH secretion gives rise to hypothalamic hypothyroidism, also called tertiary hypothyroidism, which can occur in hypothalamic disease or more rarely as an isolated defect. Hypothalamic and pituitary

\section{SÍNDROME DE SHAPIRO ASSOCIADO A HIPOTIREOIDISMO HIPOTALÂMICO}

'MD, Pediatrician; ${ }^{2} \mathrm{MD}$, Child Neurologist. 
causes of TSH deficiency are most readily distinguished by imaging methods. Although theoretically reasonable, the TRH stimulation test for the differentiation of hypothalamic disease from pituitary disease is of limited value. The typical pituitary response to TRH administration in patients with TRH deficiency is an enhanced and somewhat delayed peak, whereas the response with pituitary failure is subnormal or absent. Low free $\mathrm{T}_{4}$ without elevated TSH is consistent with central hypothyroidism ${ }^{2,3}$. We started thyroxine and cyproheptadine, and after one month the patient symptoms disappeared. We emphasize the importance of recognition the syndrome and associated endocrine manisfestations and the current treatment.

\section{REFERENCES}

1. Sheth RD, Barron TF, Hartlage PL. Episodic spontaneous hypothermia with hyperhidrosis: implications for pathogenesis. Pediatr Neurol 1994; 10:58-60.

2. Gruñeiro de Papendieck L, Iorcansky S, Rivarola MA, Heinrich JJ, Bergadá C. Patterns of TSH response to TRH in children with hypopituitarism. J Pediatr 1982;100:387-392.

3. Rapaport R, Sills I, Patel U, et al. Thyrotropin-releasing hormone stimulation tests in infants. J Clin Endocrinol Metab 1993;77:889-894. 